\title{
Kinetics of Iron (II) Removal from Aqueous Solution Using Activated Dolomite
}

\author{
G.M. Walker*, G. Connor and S.J. Allen \\ School of Chemistry and Chemical Engineering, Queen's University Belfast, Belfast BT9 5AG, Northern Ireland, UK
}

\begin{abstract}
Experimental investigations were undertaken in batch kinetic systems, for the removal of iron (II) from aqueous solutions using activated dolomite. The effect of the extent dolomite activation on the dissolution of magnesium and calcium from the dolomite lattice was determined. Under optimum experimental conditions there was a direct linear relationship between magnesium dissolution and iron (II) removal from bulk solution. The experimental data were mathematically described using empirical external mass transfer and pseudo-intra-particle diffusion models. The data show conformity with a three stage process, with the iron (II) removal rate showing good correlation with external mass transfer ( $t$ $<1 \mathrm{~min})$ and two rates of pseudo-intra-particle diffusion $(1<\mathrm{t}<90 \mathrm{mins}$, and $\mathrm{t}>90 \mathrm{mins})$.
\end{abstract}

\section{INTRODUCTION}

\subsection{The Dolomite Group of Minerals}

The Dolomite Group is composed of minerals with an unusual trigonal bar 3 symmetry. The general formula of this group is $\mathbf{A B}(\mathbf{C O 3}) 2$, where $\mathbf{A}$ can be either calcium, barium and/or strontium and the $\mathbf{B}$ can be either iron, magnesium, zinc and/or manganese [1].

The structure of the Dolomite Group is taken from the Calcite Group structure. The Calcite Group structure is layered with alternating carbonate layers and metal ion layers. The structure of the Dolomite Group minerals is layered in such a way that the A metal ions occupy one layer which is followed by a carbonate layer which is followed by the $\mathbf{B}$ metal ion layer followed by another carbonate $(\mathbf{C O 3})$ layer, etc. The layering looks like this: $|\mathbf{A}| \mathbf{C O}|\mathbf{B}| \mathbf{C O 3}|\mathbf{A}| \mathbf{C O 3}|\mathbf{B}|$ $\mathbf{C O 3}|\mathbf{A}| . .$. This ordered layering of different or nonequivalent ions causes a loss of the two fold rotational axes and mirror planes that are present in the Calcite Group structure [1].

The amount of calcium and magnesium in most specimens is equal, but occasionally one element may have a slightly greater presence than the other. Small amounts of iron and manganese are sometimes also present.

\subsection{Current Methods of Heavy Metal Removal from Wastewater}

The methods of removing heavy metals from industrial wastewater are varied. Precipitation is probably the most common of all methods of removing metals from aqueous solution. It is quite simple and is based on the fact that some metal salts are insoluble in water. Electrochemical cells are also used to precipitate metals from solution. By causing a potential between two electrodes it is possible to attract the positively charged metal ions to the cathode where they precipitate. The ion-exchange method of water treatment uses ions on a matrix to exchange with metal ions in the water.

*Address correspondence to this author at the School of Chemistry and Chemical Engineering, Queen's University Belfast, Belfast BT9 5AG, Northern Ireland, UK; Tel: +44 (0) 2890 974172; Fax: +44 (0)2890 974627; E-mail: g.walker@qub.ac.uk
This method is generally employed in a column and is capable of high levels of cleanup. Biological processes are probably the newest technologies used to treat water contaminated with heavy metals. Microbes are grown and allowed to degrade the metals dissolved in water by one of several mechanisms. Biological methods represent an area in which a great deal of innovation is taking place all the time. Finally, reverse osmosis is the simplest of all the methods discussed. This simplicity makes it a very attractive option [2].

\subsection{Thermal Processing of Dolomite}

The thermal processing or "calcining" process uses the fact that the magnesium carbonate component of the dolomite decomposes at temperatures around $800^{\circ} \mathrm{C}$. The decomposition of dolomite at $800^{\circ} \mathrm{C}$ leads to changes in the chemical composition of the surface and the porosity of the mineral $[3,4]$. Generally, the product of partial decomposition of dolomite contains calcium carbonate (calcite) and magnesium oxide and shows a significant increase in specific surface area and pore volume [5, 6, 7].

\section{EXPERIMENTAL MATERIALS AND METHODS}

\subsection{Adsorbent Characterisation}

The dolomite used in this study was mined from a deposit in Co. Fermanagh, Northern Ireland. The typical chemical composition of the dolomite in the deposit was $44 \% \mathrm{MgCO}_{3}$ and $53 \% \mathrm{CaCO}_{3}$. The dolomite was ground and sieved on a series of test sieves. The results of this analysis are illustrated in Table 1, with a mean particle size of 106 microns. The raw dolomite was charred in a furnace at $850^{\circ} \mathrm{C}$ for a period of 6-18 hours. Charring dolomite at this temperature produces a porous calcite - magnesium oxide structure. Samples of dolomite and charred dolomite were analysed for specific surface area using BET nitrogen adsorption employing a Sorptomatic 1900 (Fisons Instruments) analyser.

\subsection{Adsorbate Characterisation}

Iron sulphate (reagent grade) was used to prepare solutions of $\mathrm{Fe}(\mathrm{II})$ in de-ionised water. 
Table 1. Particle Size Distribution of Ground Dolomite

\begin{tabular}{|c|c|}
\hline Particle size range $(\mu \mathbf{m})$ & \% (w.w.) \\
\hline \hline $600-355$ & 0.1 \\
$355-250$ & 8.7 \\
$250-180$ & 3.2 \\
$180-150$ & 11.2 \\
$150-50$ & 52.2 \\
$50-$ pan & 19.3 \\
\hline
\end{tabular}

All samples were made up to a final concentration of $2 \%$ acid with spectroscopic grade nitric acid for ICP-AES analysis.

\subsection{Experimental Methods}

The mass of the selected dolomite was $0.850 \mathrm{~g} \pm 0.002 \mathrm{~g}$ in 1.7 litres of solution. The stirring motor was set to 500rpm using a tachometer each day before use. A two-blade glass impeller was used and the beaker was outfitted with four identical baffles $(0.01 \mathrm{~m}$ width) (Reactor volume $1.7 \mathrm{~L}, 0.13 \mathrm{~m}$ internal diameter, $0.13 \mathrm{~m}$ height). The experiment was timed form the moment the dolomite was added to the already stirring metal solution. Samples were drawn and filtered using a syringe and a $5 \mu \mathrm{m}$ filter. Samples of the aqueous phase were taken at regular intervals and prepared for analyses of the metal of interest and Magnesium and Calcium by ICP-AES. All samples taken were made up to $10 \mathrm{ml}$ to give a final concentration of $2 \%$ nitric acid. The $\mathrm{pH}$ was monitored throughout the kinetics experiments.

\section{ANALYSIS OF ADSORPTION KINETICS}

\subsection{External Mass Transfer Models}

A simple graphical method was used in this work to estimate the external mass transfer coefficient, $\mathrm{k}_{\mathrm{F}}$, using single resistance model [8].

In a well agitated batch adsorber mixing in the liquid is rapid, hence the concentration of the adsorbate and the concentration, $\mathrm{m}_{\mathrm{s}}$, of the particles are assumed to be uniform throughout the vessel. Consequently, $\mathrm{m}_{\mathrm{s}}$ is determined from the measured mass of adsorbent and volume of particle free liquid as shown in equation (1) below.

$m_{S}=\frac{W}{V}$

The change in fluid phase concentration with respect to time is related to the external mass transfer coefficient by:

$\frac{d C_{t}}{d t}=-k_{f} \cdot S_{S} \cdot\left(C_{t}-C_{S}\right)$

$C_{t}=C_{0}$ at $\mathrm{t}=0$

Assuming smooth spherical particles the surface area for mass transfer to the particle can be obtained from $\mathrm{m}_{\mathrm{s}} \mathrm{using}$ :

$S_{S}=\frac{6 m_{S}}{d_{p} \cdot \rho_{p} \cdot\left(1-\varepsilon_{p}\right)}$
The differential mass balance of the solute within the particle is, assuming a constant total, effective intraparticle diffusivity, $\mathrm{D}_{\mathrm{t}}$, given by:

$D_{t}\left[\frac{\partial C_{r}^{2}}{\partial r^{2}}+\frac{2}{r} \frac{\partial C_{r}}{\partial r}\right]-\rho_{p} \frac{\partial q_{e}}{\partial t}=\varepsilon_{p} \frac{\partial C_{r}}{\partial t}$

Boundary and initial conditions corresponding to the experimental conditions are given in equations, $(6,7,8)$

$D_{e}\left[\frac{\delta C_{r}}{\delta r}\right]_{r=R}=k_{f}\left(C_{t}-C_{s}\right)$

$\frac{\delta C_{r}}{\delta r}=0$ at $\mathrm{r}=0$

$\mathrm{C}_{\mathrm{r}}=0$ at $\mathrm{t}=0$ for $0<\mathrm{r}<\mathrm{R}$

Since equilibrium is assumed for adsorption at an interior site, values of $\mathrm{q}_{\mathrm{e}}$, are related to the instantaneous equilibrium expression.

$\frac{\partial q_{e}}{\partial t}=\frac{\partial}{\partial C_{r}}\left[\frac{K_{L} C_{r}}{1+a_{L} C_{r}}\right] \frac{\partial C_{r}}{\partial t}$

A solution to the equations (1-9) is as follows: since at $\mathrm{t}$ $=0, \mathrm{C}_{\mathrm{S}} \rightarrow 0$, and $\mathrm{C}_{\mathrm{t}} \rightarrow \mathrm{C}_{0}$ equation 4.3.1.1.b becomes:

$\left(\frac{d \frac{C_{t}}{C_{0}}}{d t}\right)_{t=0}=-k_{f} S_{S}$

Hence at $\mathrm{t}=0$ a plot of $\mathrm{C}_{\mathrm{t}} / \mathrm{C}_{0}$ will yield a slope of $-\mathrm{k}_{\mathrm{F}} . \mathrm{S}_{\mathrm{S}}$ from which $\mathrm{k}_{\mathrm{F}}$ can be calculated [8].

\subsection{Internal Mass Transfer Models.}

The Fick equation shown below (11) is the fundamental description for diffusion in a particle with a concentration gradient along the $\mathrm{X}$-axis $[9,10]$.

$\frac{d C}{d t}=D \frac{d^{2} C}{d X^{2}}$

In the case of spherical particle with coordinates $r, \theta$ and $\phi$, it becomes:

$\frac{d C}{d t}=\frac{1}{r^{2}}\left(\frac{\delta}{\delta r} D r^{2} \frac{\delta C}{\delta r}+\frac{1}{\sin \phi} \frac{\delta}{\delta \theta} D \sin \theta \frac{\delta C}{\delta \theta}+\frac{D}{\sin ^{2} \theta} \frac{\delta^{2} C}{\delta \phi^{2}}\right)$

This intraparticle diffusion model (single resistance) assumes:

(i) External mass transfer significant only at initial stage.

(ii) At $\mathrm{t}=0, \mathrm{C}_{0}$ equals zero.

(iii) Diffusion is radial with no variation in concentration with angular position.

The fractional uptake F can be defined as:

$F=\frac{\left(C_{0}-C_{t}\right)}{C_{0}}$

and will vary with the function: 
Table 2. Surface Area, and Fe(II) Mass Transfer Coefficients for Dolomitic Sorbents [Surface Area from BET Nitrogen Adsorption Analysis (Fisons 1900 Sorptomatic Analyser). [Dolomite Charring Temperature $=\mathbf{8 0 0}^{\circ} \mathrm{C}$ ]

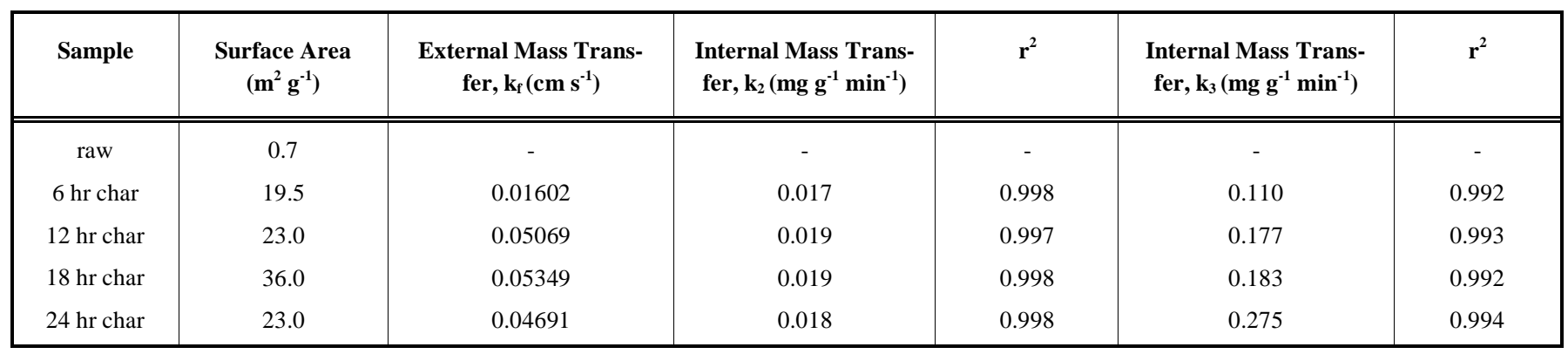

$\left[\frac{D_{0} t^{0.5}}{r^{2}}\right]$

The internal diffusion parameter, $\mathrm{k}$, can be calculated from the slope of the plot of dye adsorbed per gram of adsorbent versus time, $\mathrm{q}_{\mathrm{t}}[9,10]$.

$k=\frac{1}{t^{0.5}} * q_{t}$

where $\mathrm{q}_{\mathrm{t}}$ is defined as:

$q_{t}=\frac{\left(C_{0}-C_{t}\right)}{C_{0}} * \frac{V}{W}$

\section{RESULTS AND DISCUSSION}

\subsection{Adsorbent Characterisation}

Results of the nitrogen adsorption analysis on dolomite and charred dolomite are shown in Table 2 . These results indicate that there is a significant rise in specific surface area on charring of the dolomite due to the partial calcining process according to the following equation:

$\mathrm{CaCO}_{3} \cdot \mathrm{MgCO}_{3} \rightarrow \mathrm{MgO}+\mathrm{CO}_{2}+\mathrm{CaCO}_{3} \quad\left[800^{\circ} \mathrm{C}\right]$
The charring effectively creates a porous structure of calcium carbonate and magnesium oxide which has up to 50 times the specific surface area of the untreated dolomite. It is clear from these analyses that charred dolomite has the potential to act as an adsorbent, albeit with a relatively low surface area compared to commercial adsorbents.

\subsection{Fe (II) Adsorption}

The results of the kinetic investigation of $\mathrm{Fe}(\mathrm{II})$ sorption on charred dolomite are illustrated in (Fig. 1), as a plot of dimensionless liquid concentration versus time. The data indicate that there is a rapid reduction (up to $45 \%$ ) in aqueous $\mathrm{Fe}(\mathrm{II})$ concentration within the first 60 seconds of the experiment, after which there is a more gradual decrease of the decay curve. The data also indicate that there is a significant difference in the removal of $\mathrm{Fe}$ (II) with different dolomite char times. The 6hour charred dolomite shows significantly less removal over the first 60 seconds of the experiment with the 12 hour, 18 hour and 24 hour charred dolomite showing approximately equal initial removal. These results have been correlated to the external mass transfer coefficient, $\mathrm{k}_{\mathrm{f}}$, calculated for $\mathrm{Fe}(\mathrm{II})$ removal using the simple graphical method based on equation (10). The results of the analysis are shown in Table $\mathbf{2}$ and illustrate the divergence of the 6hour char data from the higher char times. After a period of

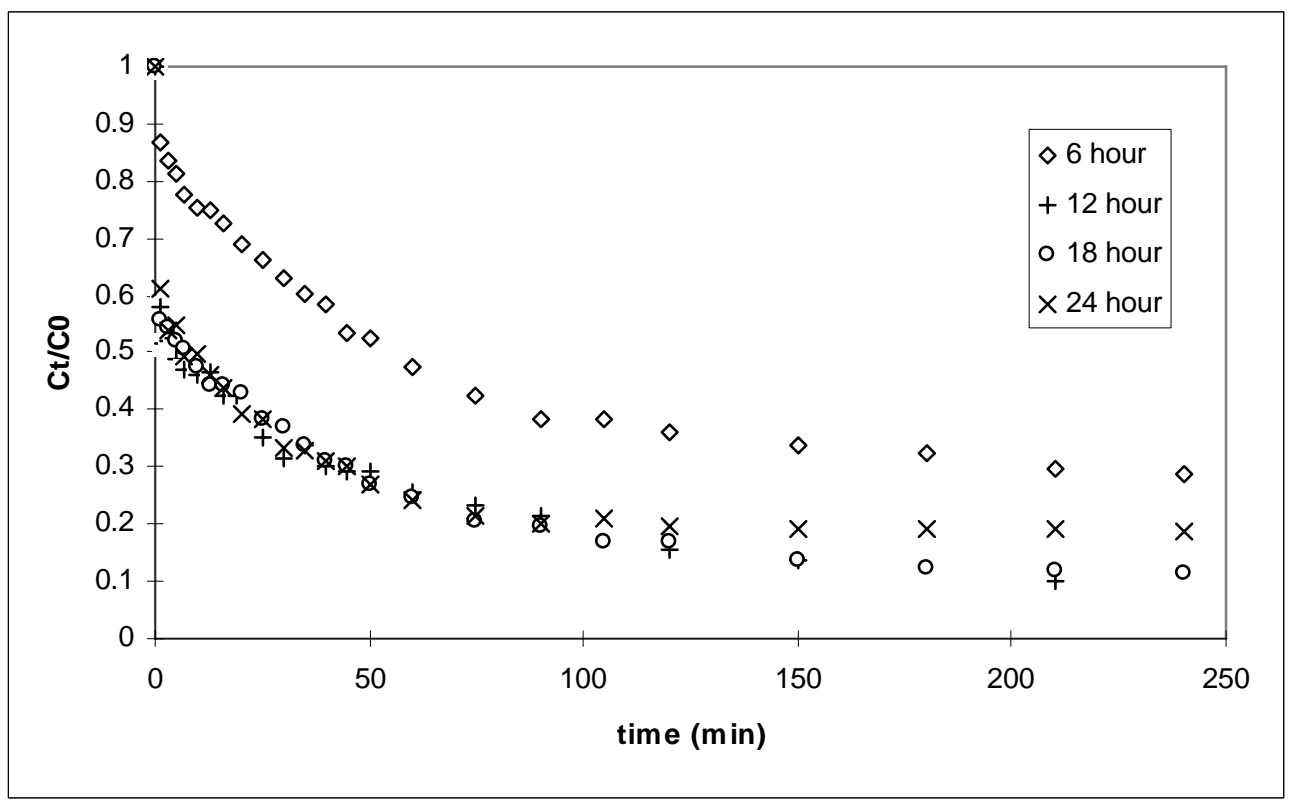

Fig. (1). Dimensionless liquid phase Fe(II) concentration versus time with variation in adsorbent char time. $(\mathrm{m} / \mathrm{V}=0.5 \mathrm{~g} \mathrm{~L})^{-1}$. 


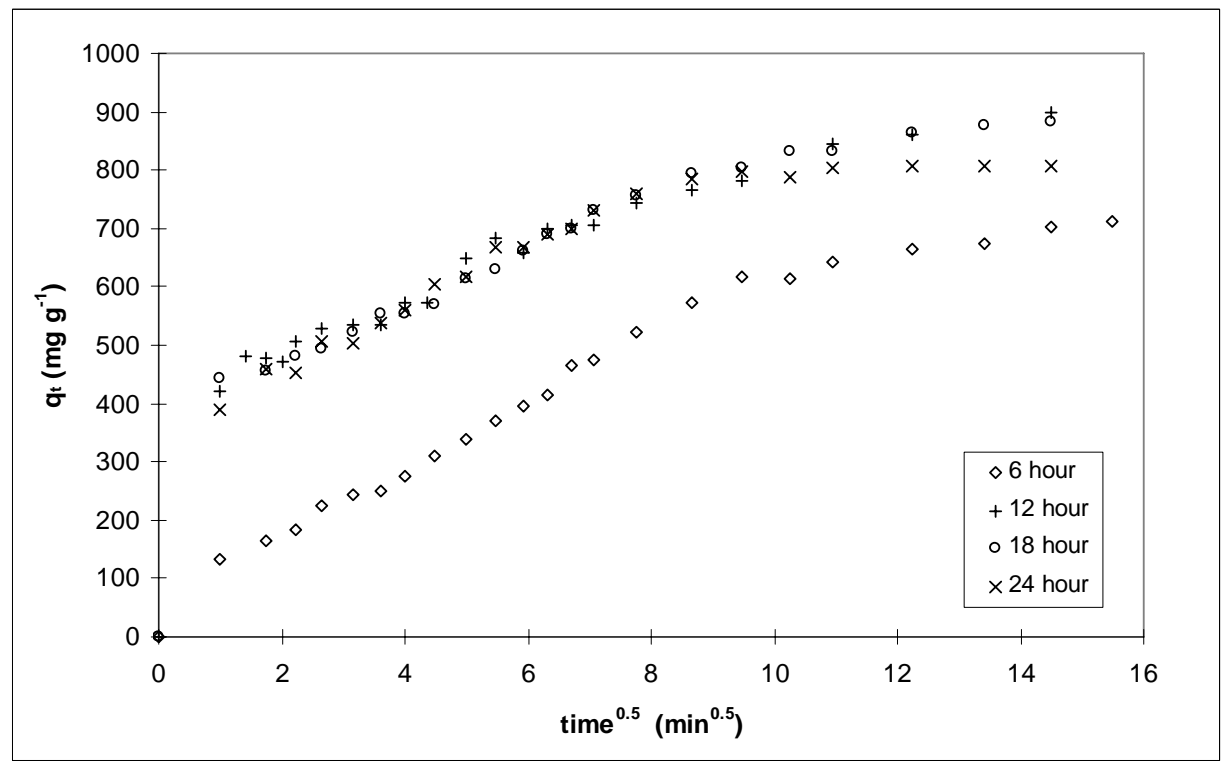

Fig. (2). Pseudo-intraparticle diffusion analysis with variation in adsorbent char time. $\left(\mathrm{m} / \mathrm{V}=0.5 \mathrm{~g} \mathrm{~L}^{-1}\right)$.

approximately 4 hours the $\mathrm{Fe}(\mathrm{II})$ removal is greatest for 12 hour and 18 hour char time followed by 24 hour then 6hour. The removal data approximately correlate with the surface area data for variation in char time (Table 2).

\subsection{Pseudo-Intra-Particle Diffusion Model}

The experimental kinetic data was also correlated using a pseudo-intra-particle diffusion model based on equation (15). The results of this analysis is illustrated in (Fig. 2) as a plot of the square root of time versus solid phase concentration, $\mathrm{q}_{\mathrm{t}}$. The data indicate that there are three distinct regions in the curve. The first region is the significant rise in solid phase concentration as $\mathrm{t} \rightarrow 0$, which has been described by the high rate of external mass transfer. A second linear region of the plot exists for $1<\mathrm{t}<\approx 90$ minutes, with a distinct third linear region for removal at $t>90$ minutes. It was noted that the $\mathrm{pH}$ of the solution initially at $\mathrm{pH}=8$, increased to $\mathrm{pH}=9$ after 10 minutes and then decreased to an equilibrium level of $\mathrm{pH}=8$ after a further period of 20 minutes.

Although the exact mechanism of the Fe (II) removal is yet to be discussed (section 4.4), the kinetics of the removal appear to follow this analysis. If we follow this pseudoadsorption analysis, the second linear region and the third linear regions would normally correlate with mass transfer in the particle macro-pores and meso-pores respectively. An indication of the high degree of linearity using this analysis is illustrated in (Fig. 3) for the second linear region. The internal diffusion parameter, $\mathrm{k}_{2}$, and the regression coefficient have been calculated for the second and third linear regions and are shown in Table 2 . The regression coefficients for the second linear region are high $r^{2}>0.97$. The third region of the plot shows a decrease in the regression coefficients for

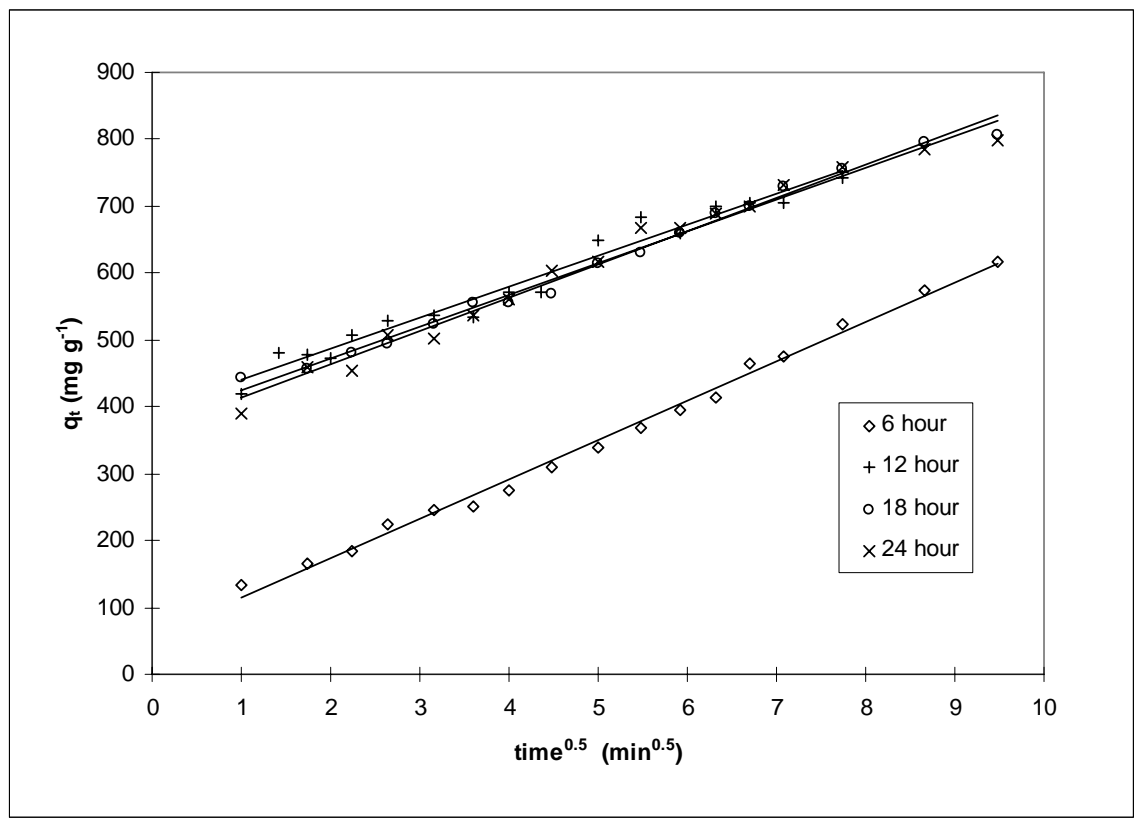

Fig. (3). Linearisation of second stage of pseudo-intraparticle diffusion analysis with variation in adsorbent char time. $\left(\mathrm{m} / \mathrm{V}=0.5 \mathrm{~g} \mathrm{~L}{ }^{-1}\right)$. 


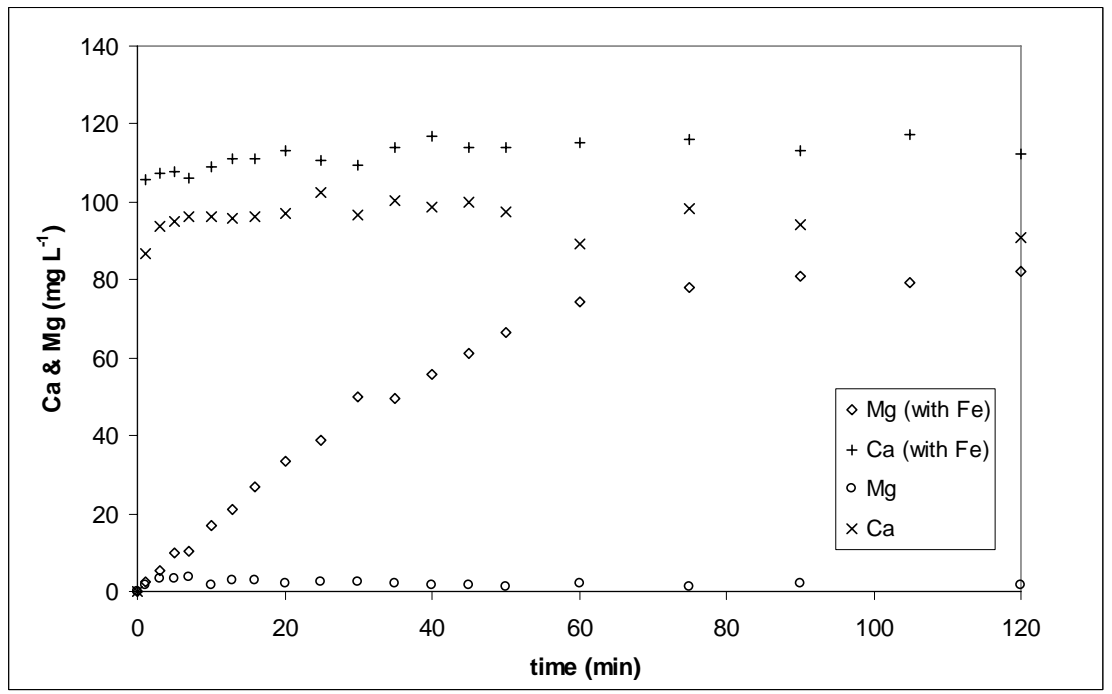

Fig. (4). Calcium and magnesium ion concentrations in solution versus time for 12 hour char $\left(\mathrm{m} / \mathrm{V}=0.5 \mathrm{~g} \mathrm{~L}^{-1}\right)$.

the third linear region are lower $r^{2}>0.92$, but are still within the range of statistical error.

The calculation of the internal diffusion parameter, $\mathrm{k}_{2}$, for the second linear region indicates that the molecular diffusion is not greatly influenced by charring time of the dolomite. The relatively low solid phase concentration of the 6 hour charred dolomite is mainly due to the lower rate of removal as $\mathrm{t} \rightarrow 0$, in fact the internal diffusion parameter in this sample is slightly higher than in the longer char times, which are almost identical $(12,18,24$ hours). The internal diffusion parameter, $\mathrm{k}_{3}$, for the third region shows more variation that $\mathrm{k}_{2}$, with generally higher diffusion found in the dolomite having lower charring time.

\subsection{Effect of Calcium and Magnesium Dissolution on Fe(II) Removal.}

During the course of the kinetic investigations for $\mathrm{Fe}(\mathrm{II})$ removal, the concentrations of $\mathrm{Mg}^{2+}$ and $\mathrm{Ca}^{2+}$ in solution were also monitored (using ICP-AES analysis). An identical blank experiment was also run with no Fe(II) present. The results of these analyses are illustrated in (Fig. 4) and indicate that rate of $\mathrm{Mg}^{2+}$ dissolution in blank sample was very low. In the case of $\mathrm{Mg}^{2+}$ dissolution in the presence of $\mathrm{Fe}(\mathrm{II})$, the concentration increased significantly with time with the rate decreasing as the experiment progressed. The concentration of $\mathrm{Ca}^{2+}$ ions remained independent of time at a relatively high concentration, with the amount of $\mathrm{Ca}^{2+}$ slightly higher in the $\mathrm{Fe}$ (II) experiment than in the blank.

The effect of the dissolution of magnesium ions on $\mathrm{Fe}(\mathrm{II})$ removal for 12 and 6 hour chars is illustrated in (Figs. 5 and 6) respectively. For the 12 hour char there was no direct relationship between $\mathrm{Fe}(\mathrm{II})$ removal and $\mathrm{Ca}^{2+}$ concentration in aqueous, however a direct relationship was observed for the 6 hour char (Fig. 6). However, for the data appear to indicate that there is a direct relationship between Fe(II) removal and the concentration of in solution, with the relationship being approximately linear (see Table $\mathbf{3}$ ).

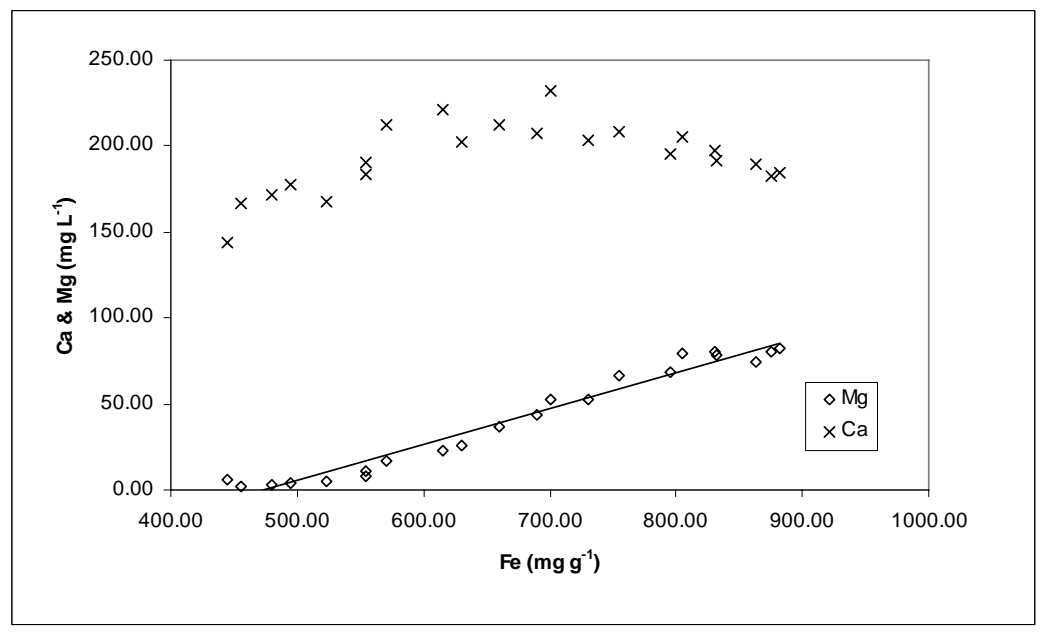

Fig. (5). Calcium and magnesium ion concentrations in solution versus iron ion uptake for 12 hour char $\left(\mathrm{m} / \mathrm{V}=0.5 \mathrm{~g} \mathrm{~L}{ }^{-1}\right)$. 


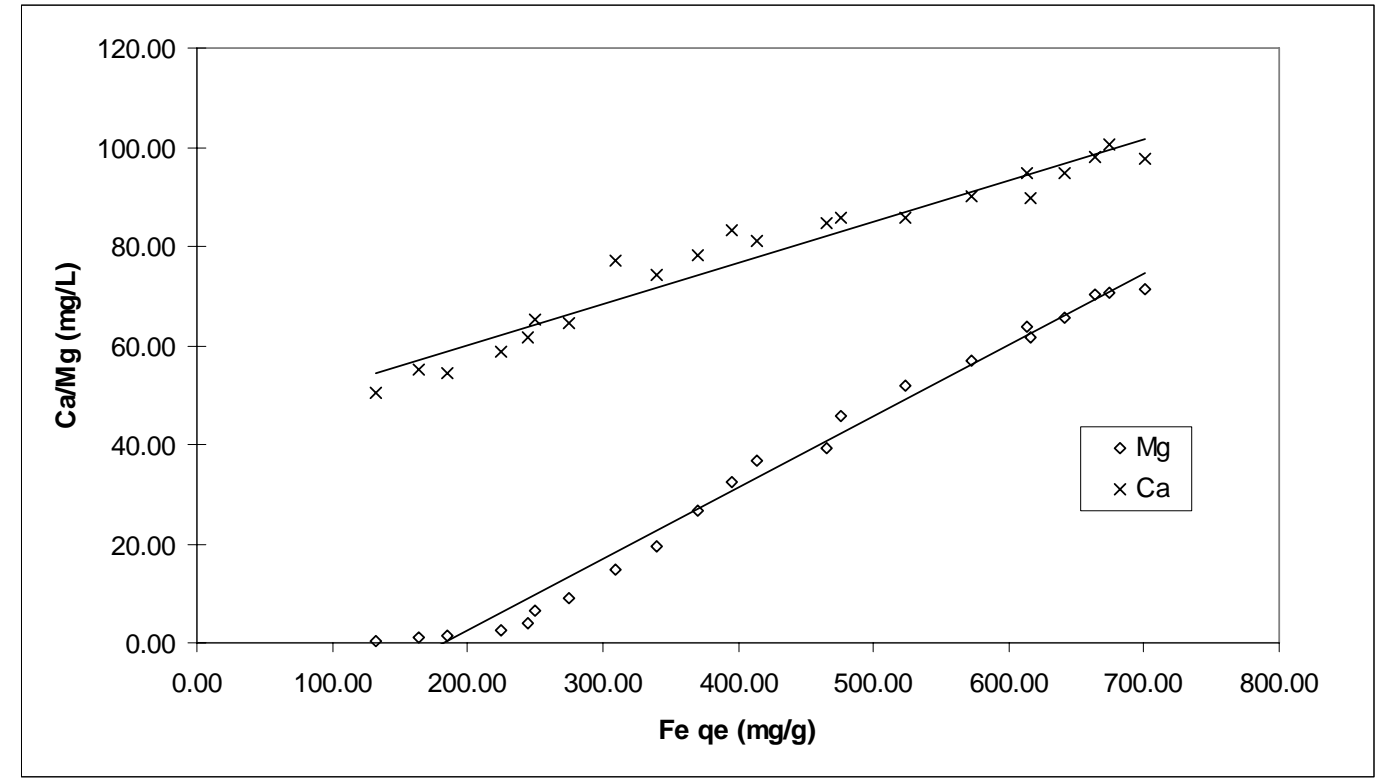

Fig. (6). Calcium and magnesium ion concentrations in solution versus iron ion uptake for 6 hour char $\left(\mathrm{m} / \mathrm{V}=0.5 \mathrm{~g} \mathrm{~L}{ }^{-1}\right)$.

Table 3. Relationship Between Magnesium Dissolution and Iron Removal

\begin{tabular}{|c|c|c|}
\hline Char Time & $\mathbf{m o l ~} \mathbf{M g}^{2+}(\mathbf{s o l n}):. \mathbf{m o l ~ F e} \mathbf{~}^{2+}($ removed $)$ & $\mathbf{r}^{2}$ \\
\hline \hline 6 hours & $1: 1.49$ & 0.985 \\
12 hours & $1: 1.16$ & 0.950 \\
18 hours & $1: 1.02$ & 0.965 \\
24 hours & $1: 1.01$ & 0.986 \\
\hline
\end{tabular}

The relationship between moles of $\mathrm{Mg}^{2+}$ dissolved in solution to moles of $\mathrm{Fe}^{2+}$ removed from solution is linear for the four char times investigated with the regression coefficient remaining quite high. The ratio appears to be reaching unity with the longer char times and it was also note that at the lower char times ( 6 hours) a linear relationship between of $\mathrm{Ca}^{2+}$ dissolved in solution to moles of $\mathrm{Fe}^{2+}$ removed was found. The accuracy of this relationship decreased with char time.

\section{CONCLUSIONS}

The effect of the extent dolomite activation on the dissolution of magnesium and calcium from the dolomite lattice was determined and under optimum experimental conditions there was a direct linear relationship between magnesium dissolution and iron (II) removal from bulk solution. The experimental data indicated that activated dolomite showed a high removal rate for iron (II) with $>600 \mathrm{mg} / \mathrm{g}$ for 6 hour activated dolomite and $>900 \mathrm{mg} / \mathrm{g}$ for dolomite produced by longer activation times. Furthermore, the experimental data were mathematically described using empirical pseudoexternal mass transfer and pseudo-intra-particle diffusion models. The data show conformity with a three stage process, with the iron (II) removal rate heavily showing good correlation with external mass transfer $(\mathrm{t}<1 \mathrm{~min})$ and two rates of pseudo-intra-particle diffusion $(1<\mathrm{t}<90 \mathrm{mins}$, and $\mathrm{t}$ $>90 \mathrm{mins}$ ).

\section{ACKNOWLEDGEMENTS}

This work was funded by the Queen's University Environmental Science and Technology Research Centre (QUESTOR).

\section{NOMENCLATURE}
$\mathrm{A}=\operatorname{area}\left(\mathrm{cm}^{2}\right)$
$a_{\mathrm{L}}=$ Langmuir isotherm constant $\left(\mathrm{dm}^{3} / \mathrm{mg}^{-1}\right)$
$\mathrm{C}=$ concentration, $\left(\mathrm{mg} / \mathrm{dm}^{3}\right)$
$\mathrm{C}_{\mathrm{e}}=$ equilibrium solute concentration, $\left(\mathrm{mg} / \mathrm{dm}^{3}\right)$
$\mathrm{C}_{\mathrm{o}}=$ initial solute concentration $\left(\mathrm{mg} / \mathrm{dm}^{3}\right)$
$\mathrm{C}_{\mathrm{r}}=$ solute concentration at a distance, $\mathrm{r}$, from the parti- cle centre, $\left(\mathrm{mg} / \mathrm{dm}^{3}\right)$
$\mathrm{C}_{\mathrm{s}}=$ solute concentration at the particle surface, $\left(\mathrm{mg} / \mathrm{dm}^{3}\right)$
$\mathrm{C}_{\mathrm{t}}=$ liquid phase concentration at time, $\mathrm{t}\left(\mathrm{mg} / \mathrm{dm}^{3}\right)$
$\mathrm{D}=$ diffusion coefficient in Fick's law
$\mathrm{D}_{\mathrm{e}}=$ effective diffusivity, $\left(\mathrm{cm}^{2} / \mathrm{s}\right)$
$\mathrm{dp}=$ average particle diameter, $(\mu \mathrm{m}, \mathrm{cm})$
$\mathrm{D}_{\mathrm{p}}=$ pore diffusivity, $\left(\mathrm{cm}^{2} / \mathrm{s}\right)$
$\mathrm{D}_{\mathrm{s}}=$ solid diffusivity, $\left(\mathrm{cm}^{2} / \mathrm{s}\right)$
$\mathrm{k}=$ intraparticle rate parameter, $\left(\mathrm{mg} / \mathrm{gmin}^{0.5}\right)$
$\mathrm{k}_{\mathrm{f}}=$ fluid-particle mass transfer coefficient, $(\mathrm{cm} / \mathrm{s})$
$\mathrm{K}_{\mathrm{f}}=$ Freundlich isotherm constant, $\left(\mathrm{dm}^{3} / \mathrm{g}\right)$
$\mathrm{K}_{\mathrm{L}}=$ Langmuir isotherm constant, $\left(\mathrm{dm}^{3} / \mathrm{g}\right)$
$\mathrm{M}=$ Mass, $(\mathrm{g})$
$\mathrm{m}_{\mathrm{s}}=$ Concentration of particle in liquid $(=\mathrm{W} / \mathrm{V})$, $\left(\mathrm{g} / \mathrm{dm}^{3}\right)$
$\mathrm{q}_{\mathrm{e}}=$ equilibrium solid phase concentration, $(\mathrm{mg} / \mathrm{g})$ 


$$
\begin{aligned}
& q=\text { average concentration of solute in particle, }(\mathrm{mg} / \mathrm{g}) \\
& r=\text { radial distance from centre of particle, } 0 \leq r \leq R \text {, }
\end{aligned}
$$

\section{GREEK SYMBOLS}

$\varepsilon_{\mathrm{p}}=$ particle voidage

$\varphi=$ spherical co-ordinate

$\theta=$ spherical co-ordinate

$\rho_{\mathrm{p}}=$ particle density, $\left(\mathrm{g} / \mathrm{cm}^{3}\right)$

\section{REFERENCES}

[1] R.S. Boynton, Chemistry and technology of lime and limestone. New York: Interscience Publishers, 1967.
[2] E.A. Jenne, (ed), Adsorption of Metals by Geomedia, Academic Press, San Diego, CA, USA, 1998.

[3] P. Staszczuk, E. Stefaniak, R. Dobrowolski, "Characterisation of thermally treated dolomite", Powder Technol., vol. 92, p. 257, 1997.

[4] E. Stefaniak, R. Dobrowolski, P. Staszczuk, "On the adsorption of chromium (VI) ions on dolomite and dolomitic adsorbents", $A d$ sorption Sci. Technol., vol. 18(2), pp. 107-15, 2000.

[5] G.M. Walker, L. Hansen, J.-A. Hanna, and S.J. Allen, "Kinetics of reactive dye adsorption onto dolomitic sorbents", Water Res., vol. 37, pp. 2081-2089, 2003.

[6] G.M. Walker, G. Connor, and S.J. Allen, "Copper II removal onto activated dolomite", Chem. Eng. Res. Des., vol. 82 (A8), pp. 961966, 2004.

[7] G.M. Walker, J.-A. Hanna, and S.J. Allen, "Treatment of Hazardous Shipyard Wastewater using Dolomitic sorbents", Water Res., vol. 39, pp. 2422-2428, 2005.

[8] G. McKay, and I.F. McConvey, "The external mass transfer of basic and acidic dyes onto wood", J. Chem. Technol. Biotechnol., vol. 31, pp. 401-8, 1981

[9] T. Furusawa, J.M. Smith, "Fluid-particle and intraparticle mass transport rates in slurries", Ind. Eng. Chem. Fundam., vol. 12(2), pp. 197-203, 1973.

[10] T. Furusawa, J.M. Smith, "Intraparticle mass transport in slurries by dynamic adsorption Studies", J. AIChE, vol. 20(1), pp. 88-93, 1974. 